\title{
Utilization of the Tail Gas and Waste Catalyst from the Petrochemical Process to Generate Syngas by Microwave-induced Technology
}

\author{
Chin Chung Lo, ${ }^{1}$ Bo-Jyun Jou, ${ }^{2}$ Tsung Yueh Tsai, ${ }^{1}$ \\ Chien Li Lee, ${ }^{3}$ and Chih-Ju G. Jou ${ }^{1 *}$ \\ ${ }^{1}$ Department of Safety, Health and Environmental Engineering, \\ National Kaohsiung University of Science and Technology, 2, Juoyue Rd, Nantz District, Kaohsiung 811, Taiwan \\ ${ }^{2}$ Department of Environmental Science and Engineering, Tunghai University, \\ No. 1727, Sec. 4, Taiwan Boulevard, Xitun District, Taichung 40704, Taiwan \\ ${ }^{3}$ Research and Development Center for Water Resource and Conservation, \\ National Kaohsiung University of Science and Technology, 2, Juoyue Rd, Nantz District, Kaohsiung 811, Taiwan
}

(Received May 6, 2018; accepted November 14, 2018)

Keywords: tail gas, waste catalyst, synthesis gas, membrane separation

In this study, membrane separation technology is used to separate hydrogen gas from tail gas and recover the exhaust energy from the petrochemical process. The results from field testing show that the concentration of hydrogen was increased from 78.7 (initial concentration) to 92-94 mol\% by adjusting the permeability pressure from 0.2 to $1.5 \mathrm{~kg} / \mathrm{cm}^{2}(\mathrm{~g})$. In addition, with microwave treatment, the spent catalyst with high coke content, obtained from the cracking or condensation reaction of hydrocarbons from a petrochemical plant, could absorb microwave energy that is converted into thermal energy to supply the heat energy required for the partial oxidation reaction. The dielectric constant and dielectric loss of the (catalyst) coke are 11.7 and 13.7 F/m, respectively. After the treatment of the waste catalyst with a microwave energy of 450 W for $10 \mathrm{~h}$, while the inlet gas ratio of $\mathrm{CH}_{4} / \mathrm{O}_{2}$ was varied from 1:1 (v/v) to 2:1 (v/v) and 1:2 (v/v), the yields were $61,81.4$, and $67.7 \%$ for hydrogen and $46,74.1$, and $52.7 \%$ for $\mathrm{CO}$, respectively. In this study, we provide an innovation idea to benefit the economy and recycle resources and integrate an overall process to reuse the tail gas, waste catalyst, and exhaust energy.

\section{Introduction}

In a petrochemical refining process, there are many process units that produce tail gas, which contains a large quantity of hydrogen and highly valuable volatile organic compounds (VOCs) $\left(\mathrm{C}_{1}-\mathrm{C}_{3}\right)$ gases. Separating and recovering those components from the tail gas and reutilizing them would convert the waste to energy (WtE). The implementation of WtE conversion together with recycling and reuse for the diversified applications not only complies with the circular economy concept, but also meets increasingly stringent environmental regulations, and brings environmental sustainability considerations and industrial operation

*Corresponding author: e-mail: george@ccms.nkfust.edu.tw https://doi.org/10.18494/SAM.2019.2084 
interests into the company's business strategic development. Recently, the development of the hydrogen economy has attracted considerable attention, especially in the secondary processing of the petrochemical refining industry since it involves a wide range of hydrogen processes. Hydrogen is an important raw material for the chemical industry, which is applied widely in petroleum chemistry, chemical fertilizer, metallurgy, and electronics industries. ${ }^{(1-4)}$ In addition, hydrogen is also the main focus of clean fuel in the foreseeable future for electric power generation and vehicle transportation. These usages are expected to result in a large increase in hydrogen demand, so hydrogen energy is considered to be the most promising clean energy in the twenty-first century. ${ }^{(4-8)}$

There are three main technologies for separating gaseous hydrogen from hydrogencontaining mixture gas, namely, pressure swing adsorption (PSA), cryogenic distillation, and membrane separation. ${ }^{(9-12)}$ Hydrogen membrane separation technology has been applied in various industries since the end of the 1970s. It has many advantages, such as flexible operation, small footprint, stable operation, low investment cost, and low energy consumption. In recent years, it has gradually replaced the high-precision separation program, which the traditional program cannot equal. ${ }^{(13-15)}$ In this study, hydrogen membrane separation was adopted as it is the most reliable and economical method that can easily be operated and has a wide range of applications; in particular, it has a small ecological footprint. ${ }^{(7,11)}$

Syngas is a mixture of $\mathrm{CO}$ and $\mathrm{H}_{2}$, which is an important raw material for the chemical industry. There are three methods of producing syngas with methane, namely, steam reforming, dry reforming, and catalytic partial oxidation. The partial oxidation method has gradually become a more promising procedure to substitute the steam reforming process for syngas production. ${ }^{(16,17)}$ There are two steps in the methane partial oxidation process. The first one is the deep oxidation of methane with oxygen from combustion, where water and carbon dioxide are produced.

$$
\mathrm{CH}_{4}+2 \mathrm{O}_{2} \rightarrow \mathrm{CO}_{2}+\mathrm{H}_{2} \mathrm{O} \quad \Delta H_{298 \mathrm{k}}=-802 \mathrm{~kJ} / \mathrm{mole}
$$

The second step involves the residual methane reacting with water and carbon dioxide to form hydrogen and carbon monoxide.

$$
\begin{gathered}
\mathrm{CH}_{4}+\mathrm{H}_{2} \mathrm{O} \rightarrow 3 \mathrm{H}_{2}+\mathrm{CO} \quad \Delta H_{298 \mathrm{k}}=206 \mathrm{~kJ} / \mathrm{mole} \\
\mathrm{CH}_{4}+\mathrm{CO}_{2} \rightarrow 2 \mathrm{H}_{2}+2 \mathrm{CO} \quad \Delta H_{298 \mathrm{k}}=247 \mathrm{~kJ} / \mathrm{mole}
\end{gathered}
$$

Its advantages include the following: (1) partial oxidation is a mild exothermic reaction. (2) The mole ratio of $\mathrm{H}_{2}$ :CO in syngas production is close to 2. This is the ideal feed rate for downstream processes such as methanol synthesis and the Fischer-Tropsch reaction. (3) The retention is a few milliseconds on the partially oxidized catalyst, which is much faster than the steam reforming process (residence time, $0.5-1 \mathrm{~s}$ ). It allows the process to achieve the same or greater productivity on less investment and low production scales. Thus, POM attracts continuous attention and has promising prospects in future development. ${ }^{(18-21)}$ 
In this study, the membrane separation method was used to recover hydrogen from the tail gas of the petrochemical refining process conducted during an in situ field test. The recovered hydrogen was used as a feedstock for hydrogen purification operation and hydrodesulfurization unit operation, and the recovered methane was used as a feed stream for syngas production. In addition, the waste catalyst treated with microwave energy was reused as the partial methane-oxidized catalyst. The carbon-containing coke with high dielectric constant absorbed microwave energy that is transformed into thermal energy to provide the heat energy required for the partial oxidation reaction. Overall, this is an innovative technology and a promising concept for recycling waste catalysts from diversified viewpoints of energy and economic efficiency.

\section{Experiment Instrument and Method}

\subsection{Instrument}

The petrochemical refining process unit was utilized to perform the in situ field test, and the tail gas passed through the filter and then fed into the membrane separation device, which was made of polyamide. The membrane module was $100 \mathrm{~cm}$ in length and $15.24 \mathrm{~cm}$ in diameter and consisted of 4000 pieces of hollow fibers with an outer diameter of 300-450 $\mu \mathrm{m}$ and an inner diameter of 150-200 $\mu \mathrm{m}$. The inlet pipe was made of ASTM316 seamless stainless steel tubing with an inner diameter of $1.27 \mathrm{~cm}$ as shown in Fig. 1.

Furthermore, a proportional-integral-derivative (PID) controller was connected to a microwave oven of $2.45 \mathrm{GHz}$ frequency and $750 \mathrm{~W}$ maximum output power. The $80 \mathrm{~mL}$ reactor made of quartz glass with 40 tiny holes at the bottom was used for waste Pt catalyst treatment as shown in Fig. 2. The waste catalyst (particle diameter of $1.5-1.6 \mathrm{~mm}$ ) was obtained from the catalyst reforming process in the petrochemical refining process, which had a coke content higher than $25 \mathrm{wt} \%$ and $\mathrm{Pt}$ content of about $0.3 \mathrm{wt} \%$.

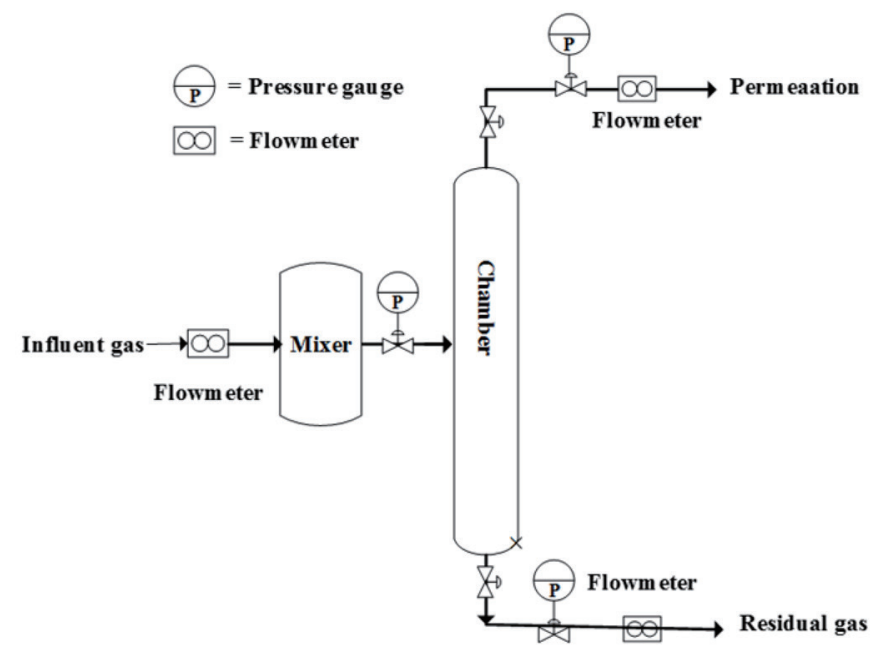

Fig. 1. Schematic diagram of the experimental gas separation facility. 


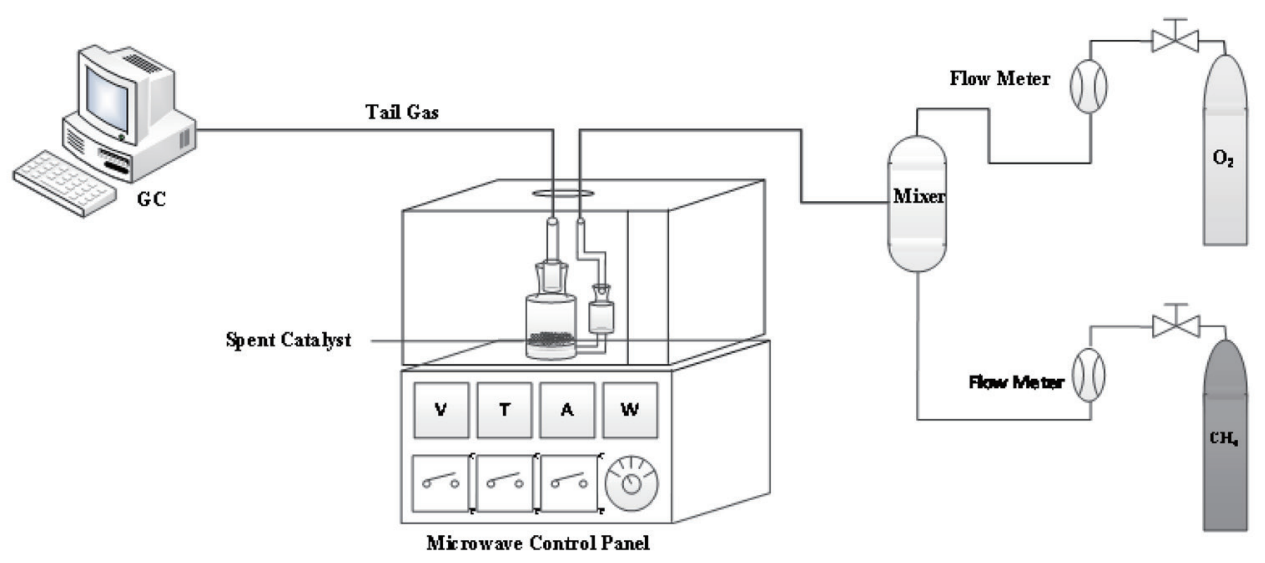

Fig. 2. Diagram of the experiment setup.

\subsection{Experimental method}

During the in situ field test, the compositions of the tail gas in mole percent were obtained; the composition was determined on average to consist of $78.7 \% \mathrm{H}_{2}, 4.1 \% \mathrm{CH}_{4}, 3.8 \% \mathrm{C}_{2} \mathrm{H}_{6}$,

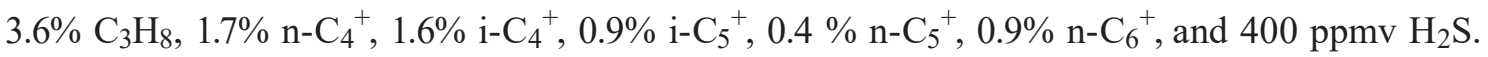
The following experimental conditions were tested: When the intake pressure and flow rate were kept constant at $2.8 \mathrm{~kg} / \mathrm{cm}^{2}(\mathrm{~g})$ and $380 \mathrm{~L} / \mathrm{min}$, respectively, the gas permeation pressure was varied from 0.2 to $0.5,1$, and $1.5 \mathrm{~kg} / \mathrm{cm}^{2}(\mathrm{~g})$. When the intake pressure and gas permeation pressure were kept constant at 2.5 and $0.5 \mathrm{~kg} / \mathrm{cm}^{2}(\mathrm{~g})$, respectively, the intake flow rate was adjusted from 400 to 457,500 , and $540 \mathrm{~L} / \mathrm{min}$.

An impedance analyzer (Agilent Co., 4291B) was used to measure the dielectric constant and dielectric loss constant to be respectively 11.7 and $13.7 \mathrm{~F} / \mathrm{m}$ for the waste platinum catalyst at a frequency of $2.45 \mathrm{GHz}$ at $25{ }^{\circ} \mathrm{C}$. Then, $20 \mathrm{~g}$ of the waste platinum catalyst was placed in the quartz glass reactor at a microwave power of $450 \mathrm{~W}$ for $10 \mathrm{~h}$ continuously with the air and methane mixture passing through the bottom of the reactor. The hydrogen and $\mathrm{CO}$ yields were determined under the following conditions: The intake volume ratio of $\mathrm{CH}_{4} / \mathrm{O}_{2}$ was adjusted from 1:1 to 2:1 to $1: 2(\mathrm{~mL} / \mathrm{min})$, while the intake volume ratio of $\mathrm{CH}_{4}+\mathrm{H}_{2}(0.9: 0.1 \mathrm{~mole} \%) / \mathrm{O}_{2}$ was maintained at 1:1.

\section{Results and Discussion}

\subsection{Effect of permeability pressure on hydrogen concentration}

The capability of gas diffusion can be explained by the solubility-diffusion theory. The differential partial pressure of gas molecules between the two sides of the membrane is the driving force of the permeation process. The greater the pressure difference, the greater the driving force of the gas permeation process, resulting in higher gas production and recovery rates. When the intake pressure of the tail gas was $2.8 \mathrm{~kg} / \mathrm{cm}^{2}(\mathrm{~g})$ and the flow rate was 
$380 \mathrm{~L} / \mathrm{min}$, the permeated gas pressure was gradually adjusted from 0.2 to $0.5,1.0$, and 1.5 $\mathrm{kg} / \mathrm{cm}^{2}(\mathrm{~g})$. Figure 3 shows that the permeated hydrogen gas was purified by increasing the permeated gas pressure. When the permeated gas pressure increased from 0.2 to $1.5 \mathrm{~kg} / \mathrm{cm}^{2}(\mathrm{~g})$, the hydrogen purity increased from 92 to $94 \mathrm{~mol} \%$, whereas the hydrogen recovery rate dropped from 34.2 to $19.6 \%$.

\subsection{Effect of intake flow rate on hydrogen concentration}

Theoretically, the higher the inlet flow rate, the higher the permeated gas flow rate; with the higher permeated gas concentration, more hydrogen molecules were recovered. However, the recovery rate was reduced, as shown by the experimental results. The following experiments were carried out at the intake pressure, and permeated gas pressure kept constant at 2.5 and 0.5 $\mathrm{kg} / \mathrm{cm}^{2}(\mathrm{~g})$, respectively, and then the intake flow rate was changed from 400 to 457, 500, and $540 \mathrm{~L} / \mathrm{min}$.

Figure 4 shows that the permeated hydrogen concentration increased with the intake flow rate. When the intake flow rate increased from 400 to $540 \mathrm{~L} / \mathrm{min}$, the hydrogen concentration increased from 87 to $98 \mathrm{~mol} \%$; however, the recovery rate slightly decreased from 53.7 to $51.1 \%$.

\subsection{Effect of $\mathrm{CH}_{4} / \mathrm{O}_{2}$ intake flow rate on hydrogen concentration}

The catalytic partial oxidation process of methane consists of two-step reactions. The first step is deep oxidation, which is an exothermic reaction in which methane reacts with oxygen molecules to form carbon dioxide and water. The second step is the reforming process where the residual methane combines with $\mathrm{H}_{2} \mathrm{O}$ and $\mathrm{CO}_{2}{ }^{(22)}$ The reforming process is an endothermic reaction, where the required heat energy is supplied by the first step (the exothermic process). On the other hand, the waste platinum catalyst was used in the catalytic partial oxidation reaction. The coke that is deposited on the surface or voids of the catalyst has the characteristics

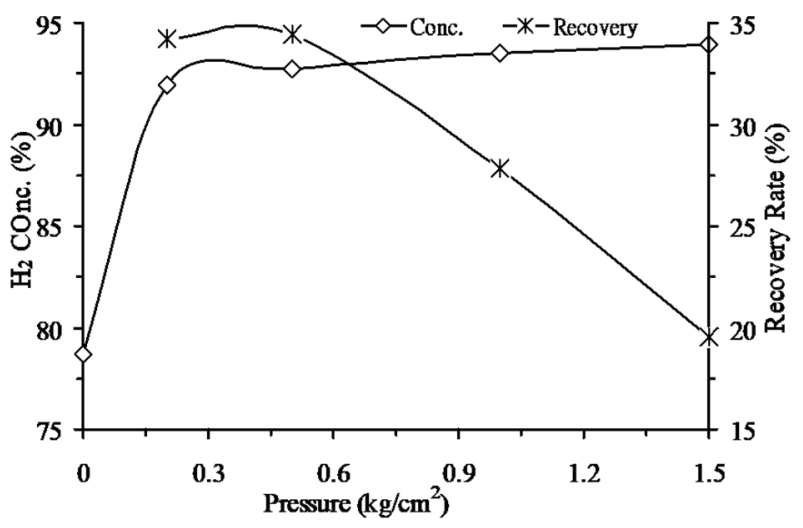

Fig. 3. Permeated hydrogen concentration and recovery efficiency vs permeation pressure.

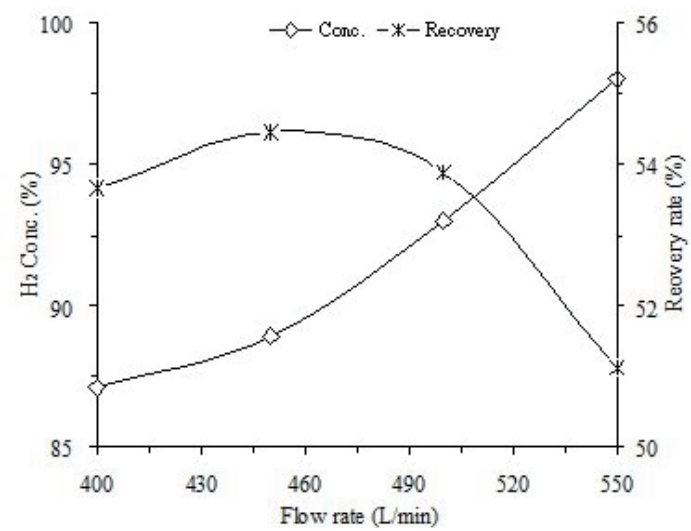

Fig. 4. Permeated hydrogen concentration and recovery efficiency vs inlet flow rate. 
of high dielectric constant and dielectric loss constant of 11.7 and $13.7 \mathrm{~F} / \mathrm{m}$, respectively. It absorbed microwave energy that is converted into heat energy to provide the thermal energy required for the reaction. At a microwave power of $450 \mathrm{~W}$ for $10 \mathrm{~h}$ exposure, Figs. 5 and 6 show that the hydrogen and $\mathrm{CO}$ yields were 61 and $46 \%$, respectively, when the influent volumetric ratio of $\mathrm{CH}_{4} / \mathrm{O}_{2}$ was $1: 1$. When the influent volumetric ratio of $\mathrm{CH}_{4} / \mathrm{O}_{2}$ was changed to $1: 2$, more oxygen molecules were available to react with methane for oxidation thus providing the heat energy required for the coke combustion. Moreover, heat transport by convection was faster through the medium bed with the less contact time of the catalyst reaction, so hydrogen and $\mathrm{CO}$ yields only slightly increased to 67.7 and $52.7 \%$, respectively. The $\mathrm{CH}_{4} / \mathrm{O}_{2}$ influent volumetric ratios were also set to $2: 1$, which means that few oxygen molecules but more methane molecules were available in the reactor as combustible fuel. This results in a relatively high surface temperature of the catalyst, enhancing the reformation reaction. The hydrogen and CO yields were 81.4 and $74.1 \%$, respectively.

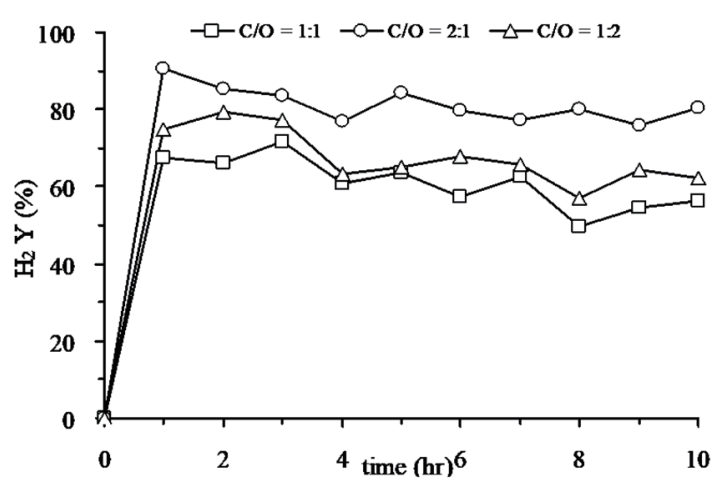

Fig. 5. Relationship between the intake volume ratio of $\mathrm{CH}_{4} / \mathrm{O}_{2}$ and the yield of hydrogen.

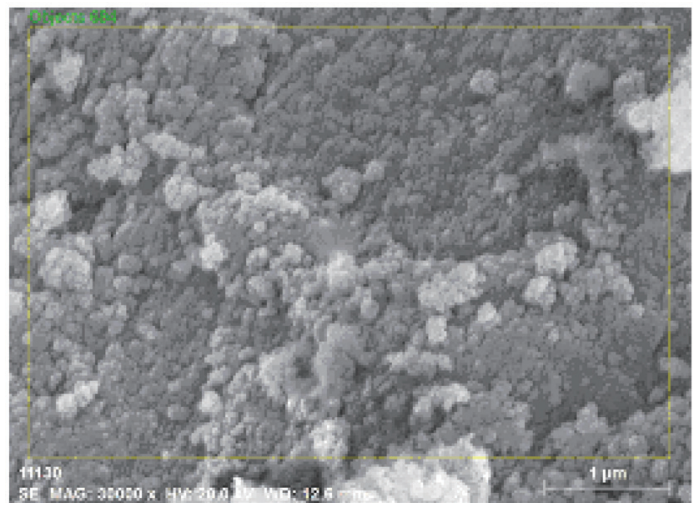

(a)

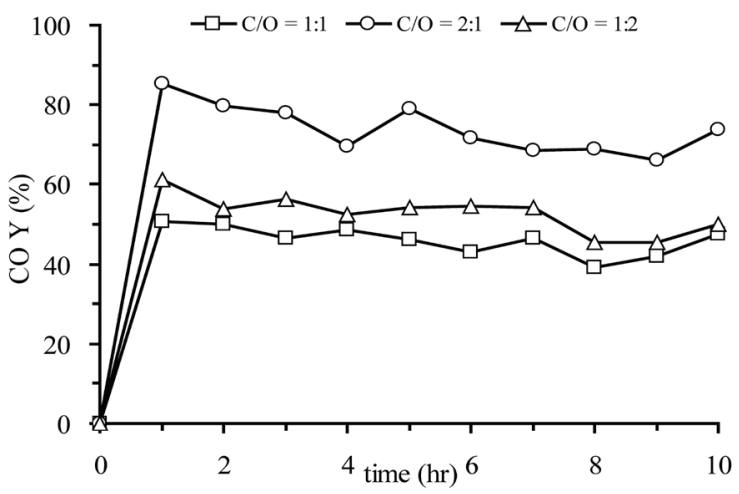

Fig. 6. Relationship between the intake volume ratio of $\mathrm{CH}_{4} / \mathrm{O}_{2}$ and the yield of $\mathrm{CO}$.

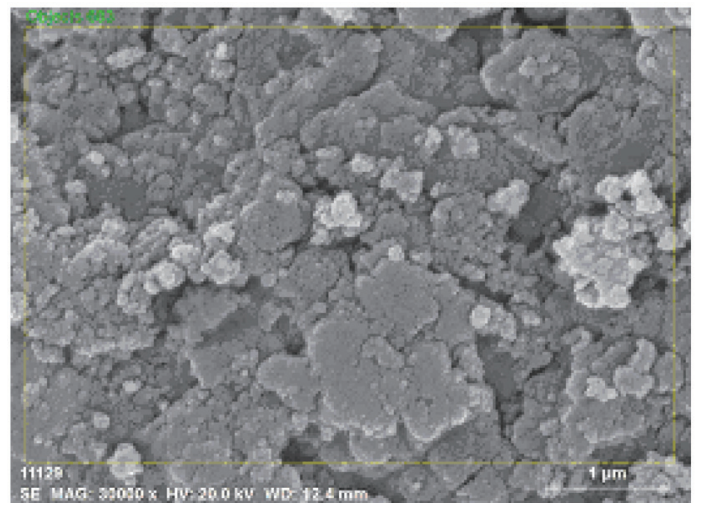

(b)

Fig. 7. (Color online) Waste catalyst SEM images: (a) waste catalyst and (b) reuse of waste catalyst as partial oxidation reaction. 


\subsection{Analysis of the waste catalyst structure}

At a microwave power of $450 \mathrm{~W}$ for $10 \mathrm{~h}$ exposure with an influent volumetric $\mathrm{CH}_{4} / \mathrm{O}_{2}$ ratio of $1: 1$, the coke content of the catalyst increased from 30.5 to $37.8 \mathrm{wt} \%$. Figures 7(a) and 7(b) show distinct changes in the SEM images with respect to the coke deposited on the surface. The flat structure was more significant on the waste catalyst used for the partial oxidation reaction.

\section{Conclusions}

In this research, the membrane separation technology is used to recover hydrogen from the exhaust of petrochemical industry tail gas during the polyimide manufacturing process. Field test results show that when the permeability pressure was adjusted from 0.2 to $1.5 \mathrm{~kg} / \mathrm{cm}^{2}(\mathrm{~g})$, the hydrogen purity increased from 92 to 94 mole\%. The recovered hydrogen could be used as a feedstock for hydrogen purification and hydrodesulfurization operation units.

In addition, when treated with microwave power (the coke has dielectric and dielectric loss constants of 11.7 and $13.7 \mathrm{~F} / \mathrm{m}$, respectively), the coke deposits absorbed microwave energy that is transformed into thermal energy. Hence, thermal energy was utilized as the heat source of the catalytic partial oxidization process by the spent catalyst. These results show that at inlet volume ratios of $\mathrm{CH}_{4} / \mathrm{O}_{2}$ of 1:1, 2:1, and 1:2, the hydrogen gas yields were determined to be 61 , 81.4, and $67.7 \%$, whereas the $\mathrm{CO}$ yields were determined to be $46,74.1$, and $52.7 \%$, respectively, at a microwave energy of $450 \mathrm{~W}$ for $10 \mathrm{~h}$ exposure. In this study, we integrated the use of discarded energy products, both the tail gas and the waste catalyst, from the petrochemical manufacturing process. It is an innovative concept from the diversified viewpoints of energy efficiency, economy, and waste catalyst regeneration.

\section{References}

1 A. R. Choudhuri and S. R. Gollahalli: Int. J. Hydrogen Energy 25 (2000) 451. https://doi.org/10.1016/S03603199(99)00027-0

2 J. H. Moon, J. H. Bae, Y. J. Han, and C. H. Lee: J. Membrane Sci. 356 (2010) 58. https://doi.org/10.1016/ j.memsci.2010.03.027

3 J. H. Moon, J. H. Bae, Y. S. Bae, J. T. Chung, and C. H. Lee: J. Membrane Sci. 318 (2008) 45. https://doi. org/10.1016/j.memsci.2008.02.001

4 A. K. Jain, N. K. Achary, V. Kulshreshth, K. Awasthi, M. Singh, and Y. K. Vijay: Int. J. Hydrogen Energy 33 (2008) 346. https://doi.org/10.1016/j.ijhydene.2007.07.036

5 M. İlbas, İ. Y1lmaz, and Y. Kaplan: Int. J. Hydrogen Energy 30 (2005) 1139. https://doi.org/10.1016/ j.ijhydene.2004.10.016

6 G. J. Rørtveit, J. E. Hustad, S. C. Li, and F. A. Willams: Combust. Flame 130 (2002) 48. https://doi.org/10.1016/ S0010-2180(02)00362-0

7 A. L. Khan, A. Cano-Odena, B. Gutiérrezb, C. Minguillónb, and I. F. J. Vankelecom: J. Membrane Sci. 350 (2010) 340. https://doi.org/10.1016/j.memsci.2010.01.009

8 P. Dufresne: Appl. Catal., A 322 (2007) 67. https://doi.org/10.1016/j.apcata.2007.01.013

9 J. W. Phair and S. P. S. Badwal: Sci. Technol. Adv. Mater. 7 (2006) 792. https://doi.org/10.1016/j.stam.2006.11.005

10 Y. Jiao, H. Su, and W. Hou: Control Eng. Pract. 20 (2012) 1075. https://doi.org/10.1016/j.conengprac.2012.04.010

11 O. C. David, D. Gorri, A. Urtiag, and I. Ortiz: J. Membrane Sci. 378 (2011) 359. https://doi.org/10.1016/ j.memsci.2011.05.029

12 K. Díaz, M. López-González, L. F. del Castillo, and E. Riande: J. Membrane Sci. 383 (2011) 206. https://doi. org/10.1016/j.memsci.2011.08.042 
13 W. Chang and T. Y. Lee: Chem. Eng. Sci. 61 (2006) 3974. https://doi.org/10.1016/j.ces.2006.01.037

14 F. Dorosti, M. R. Omidkhah, M. Z. Pedram, and F. Moghadam: Chem. Eng. J. 171 (2011) 1469. https://doi. org/10.1016/j.cej.2011.05.081

15 H. W. Kim and H. B. Park: J. Membrane Sci. 372 (2011) 116. https://doi.org/10.1016/j.memsci.2011.01.053

16 Y. Ji, W. Li, H. Xu, and Y. Chen: Appl. Catal., A 213 (2001) 25. https://doi.org/10.1016/S0926-860X(00)00887-5

17 J. H. Jun, T. H. Lim, S. W. Nam, S. A. Hong, and K. J. Yoon: Appl. Catal., A 312 (2006) 27. https://doi. org/10.1016/j.apcata.2006.06.020

18 S. M. Hashemnejad and M. Parvari: Chin. J. Catal. 32 (2011) 273. https://doi.org/10.1016/S1872-2067(10)601751

19 M. Khajenoori, M. Rezaei, and B. Nematollahi: J. Ind. Eng. Chem. 19 (2013) 981. https://doi.org/10.1016/ j.jiec.2012.11.020

20 J. Xu, W. Wei, A. Tian, Y. Fan, X. Bao, and C. Yu: Catal. Today 149 (2010) 191. https://doi.org/10.1016/ j.cattod.2009.07.087

21 W. Z. Weng, M. S. Chen, Q. G. Yan, T. H. Wu, Z. S. Chao, Y. Y. Liao, and H. L. Wan: Catal. Today 63 (200) 317. https://doi.org/10.1016/S0920-5861(00)00475-2

22 M. Peymani, S. M. Alavi, and M. Rezaei: Int. J. Hydrogen Energy 41 (2016) 6316. https://doi.org/10.1016/ j.ijhydene.2016.03.033 